\title{
KANBAN SIMULATION MODEL FOR PRODUCTION PROCESS OPTIMIZATION
}

\author{
UDC: 658.5 \\ Original Scientific Paper \\ Riste GOLCHEV ${ }^{1}$, Bojan JOVANOSKI ${ }^{2}$, Valentina GECHEVSKA $^{1}$, Robert MINOVSKI $^{1}$ \\ ${ }^{1}$ Ss. Cyril and Methodius University in Skopje, Faculty of Mechanical Engineering, Department of Industrial \\ Engineering and Management, 1000 Skopje, Karpos II bb, Republic of Macedonia. \\ ${ }^{2}$ Ss. Cyril and Methodius University in Skopje, Faculty of Mechanical Engineering, Department of Industrial \\ Engineering and Management, 1000 Skopje, Karpos II bb, Republic of Macedonia. \\ E-mail: bojan.jovanoski@mf.edu.mk
}

Paper received: 30.10.2015.; Paper accepted: 21.11.2015.

\begin{abstract}
A long time has passed since the KANBAN system has been established as an efficient method for coping with the excessive inventory. Still, the possibilities for its improvement through its integration with other different approaches should be investigated further. The basic research challenge of this paper is to present benefits of KANBAN implementation supported with Discrete Event Simulation (DES). In that direction, at the beginning, the basics of KANBAN system are presented with emphasis on the information and material flow, together with a methodology for implementation of KANBAN system. Certain analysis on combining the simulation with this methodology is presented. The paper is concluded with a practical example which shows that through understanding the philosophy of the implementation methodology of KANBAN system and the simulation methodology, a simulation model can be created which can serve as a basis for a variety of experiments that can be conducted within a short period of time, resulting with production process optimization.
\end{abstract}

Keywords: KANBAN, manufacturing, simulation, methodology for KANBAN implementation, process optimization.

\section{INTRODUCTION}

There is no doubt that the Japanese management principles, philosophies, methodologies and methods had a deep impact on the functioning of organizations in general, (Ohno \& Bodek, 1988; Pisuchpen, 2012; Sugimori \& Kusunoki, 1977). Toyota Production System (Monden, 1998), is the main frame of those approaches. KANBAN as a part of JIT (Welgama et al., 1995) is probably one of the most famous parts of the Toyota Production System, since it directly copes with the waste of creating extra inventory, affecting and reducing all other wastes in production. It is also a fact that acceptance of those approaches in the companies in underdeveloped countries is not on the desired level. On the other hand, they are facing serious problems concerning the insufficient or excessive production, on time delivery, generating extra inventory etc. In general, companies have issues coping with the management of the overall production processes. Furthermore, managers are often conservative when changes in their management concepts are the topic of discussion. Namely, it is more than clear that implementation of KANBAN is accompanied by serious prerequisites for its implementation: detailed design of processes, standardization of the operations and smooth production, (Monden, 1998). Fulfillment of these prerequisites needs huge investment in all kind of resources, leading to significant time and money expenditure. This is frequently a reason for leaving the initial idea for KANBAN implementation. This article is based on a basic research for possibilities for KANBAN implementation in one metal-working company. In that direction, the basic aim of the article is to present benefits of combined implementation of KANBAN system and methodology for Discrete Event Simulation (DES). After giving the brief theory on KANBAN and DES, the article discusses the options for their integration. The case at the 
end is focused on one production line in one metalworking company and experiments with the container capacity which directly affects the number of KANBANs.

\section{KANBAN PHILOSOPHY}

The word KANBAN comes from two Japanese words: KAN- Signal and BAN-Card or Board, hence KANBAN is considered to actually be a signal card. KANBAN is defined in the following way:

The KANBAN system represents the information system JIT (Just in Time), which provides management of the production flow in the manufacturing process in the required/needed quantities for each processneither too many or too little of the needed products, (Minovski, 2007).
The basic information carrier within the KANBAN system is a rectangular card, enveloped in a plastic case, called a KANBAN card, Figure 1. The KANBAN card is always attached to the container that contains the parts for which the card is intended. For this paper, the information stored in the "Container capacity" field is of crucial importance for the process and the simulation model.

The KANBAN system represents a pulling system and its mechanism moves the information in the opposite direction from the next work station, while the materials move conversely from the information of the previous work station to the next one, aided by the KANBAN cards. A generic scheme with only two working stations is presented in Figure 2. The same concept can be transferred to $\mathrm{n}$ working stations.

\begin{tabular}{|l|c|}
\hline KANBAN Card Type - P & Id. No. 35/2015 \\
\hline Product Type & Metal cabinet \\
\hline Container Type & Metal, 2 x 1 m \\
\hline Container capacity & 35 \\
\hline Storage location & A - 2 \\
\hline Previous Process & Punching \\
\hline Next Process & 3 days \\
\hline Production cycle & R. G. \\
\hline Planner & $25 / 03 / 2015$ \\
\hline Released on & Machine processing CNC lathe \\
\hline
\end{tabular}

Figure 1: KANBAN card



Legend :


Figure 2: Information and material flow in the KANBAN system (Lödding, 2013) 
When the client takes the pulled product, the KANBAN card moves in the opposite direction, towards the KANBAN board on Work Station 2, signalizing that the reproduction of the pulled product should begin. In order to make the pulled product, the operator on Work Station 2, pulls materials from Work Station 1, and the KANBAN card for those materials moves to the KANBAN board on Work Station 1, allowing the reproduction of the pulled material to begin on Work Station 2.

\section{IMPLEMENTATION OF KANBAN SYSTEM METHODOLOGY}

One possible methodology for the purpose of systemized and easier implementation of the KANBAN system is presented, consisting of seven fundamental phases as shown in the flow chart in Figure 3.



Figure 3: Methodology for KANBAN implementation (Gross \& McInnis, 2003)

This presented methodology seems fairly simple; however, its implementation is a challenge, because in order to be certain that the KANBAN system is well-designed, a variety of stochastic, not to mention expensive, calculations and iterations must be made, (Müller et al., 2012).

There are number of possible tools in order to determine the best KANBAN system, but also to experiment with it. One of them is the simulation and its advantage in experimenting with and optimizing performance values. Since there are many variables to experiment with, the simulation shortens the time needed to determine the possible outcomes of the system in different situations, (Hao \& Shen, 2008). For the most part, simulations are more than useful in the first three steps of the methodology, especially in the third one, during the actual design of the KANBAN system. This paper is focused on these three steps. As it was stated before, the simulation was used in order to determine the capacity of the container, or the number of KANBAN cards needed in order to achieve a more effective production process.

The creation of the simulation model shown below is based on the methodology according to (Banks et al., 2004) a methodology that offers a systemized approach. As a result of the characteristics of the methodology and because its steps are not strictly successive, it allows adjustments to different application. Because of the space limitation of the paper, not all methodology steps are explicitly presented.

\section{KANBAN SIMULATION MODEL}

The following part presents the application of the KANBAN system in a simulation model made with the software suite Technomatix Plant Simulation, (Siemens). Using Banks's methodology, each and every problem is defined during the first step. Then, goals are set and a model is conceptualized according to the acquired information. After formulating the model, experiments which in normal circumstances might last for days, months or even years are created in just few minutes. If after the result analysis it is concluded that the experiment data are sufficient and correct, records are prepared and the final step, implementing the solution, can be made.

\section{Defining the problem: Unbalanced Production}

Although the KANBAN system indirectly influences the resolutions of many problems throughout the entire production processes, it should be noted that KANBAN is commonly associated with overproduction or unbalanced production. 


\section{Purpose of the simulation model: Determining optimal KANBAN container capacity in relation to the demand}

The purpose of this simulation model is through simulation of a number of possible production scenarios with previously determined settings, to get an optimal capacity of a KANBAN container, in relation with the daily needed throughput. This is extremely important because the containers are the ones that when empty, initialize the beginning of the production, and when they are full they stop it. Furthermore, the storage units are an additional burden when it comes to space usage. In order to avoid the main and the biggest problem (to avoid overproduction) it is immensely important to design a precise KANBAN system.

Figure 4 shows the basic concept of setting the elements in the simulation model, (Robinson, 2004). The information moving direction, as well as the direction of the product can be clearly noticed on the figure, starting with the raw materials and ending in the hands of the customer.
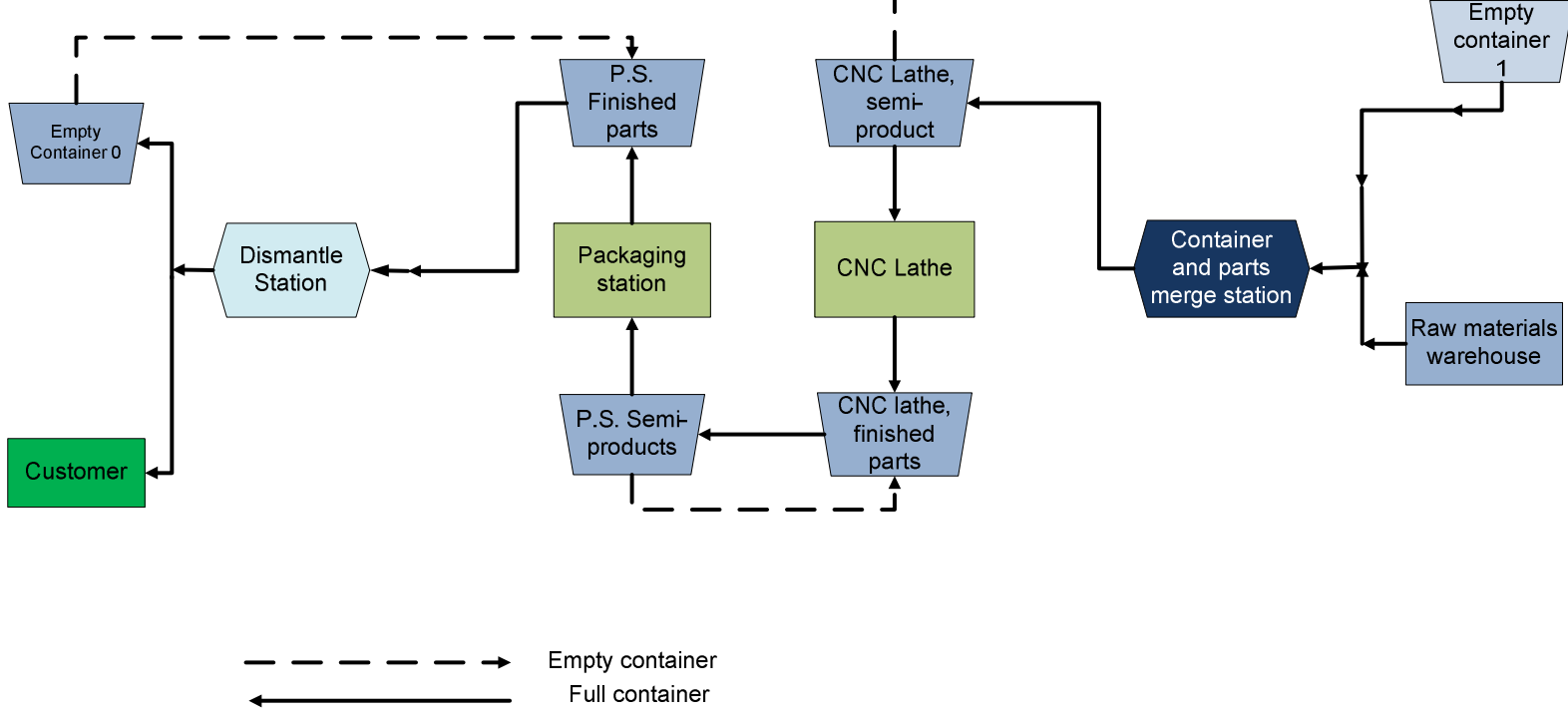

Figure 4: Basic concept of the simulation model

The following basic settings for the simulation model are set:

- Processing time for CNC lathe and Packaging station $=1$ minute $100 \%$ availability

- Dismantle station: Station where the products are separated from the containers with successor 1

- Empty container 0 with successor 2

- Customer: The place where the final products leave the system

- 1 simulation cycle $=3$ work shifts $* 8$ hour shifts

The production flow is defined as follows:

The container is located on the Dismantle station where it is gradually emptied. If the container is empty (Empty container 0), it will be transferred to the spot for P.S. Finished parts. The container's arrival signalizes the need for the beginning of the Semi-Product processing. This occurs in such a manner that the now empty container from the spot P.S. Semi-Products is transferred to the spot CNC Finished Parts, where it receives the final products from CNC Finished Parts to Empty Container 1. The Container and parts merge (filling the container with parts) and it takes it back to the spot CNC Lathe Semi-Product. The arrival of the container initializes the beginning of production on the CNC Lathe. If the CNC Lathe finished parts container is full, the container will be sent to the spot for Semi-Products on P.S. Semi product. The finished products from the Packaging station will then be sent to the Dismantle station. The KANBAN containers are the ones that initialize and control the beginning and end of the production process. KANBAN containers contain all the needed information in this simulation model.

\section{EXPERIMENT}

After the simulation model presented in the previous chapter is verified and validated, the next step entails conducting experiments and analyzing its outcomes. 
In Figure 5, the results of simulating 13 different cycles are presented. The ordinate lists the daily throughputs done in 3 shifts, 8 hours each, while the abscissa shows the values for which the KANBAN container is limited.

First, it can be noticed that by decreasing the container's capacity, daily throughput does not decrease proportionally. Instead, there are occasions when a container with different capacity, has identical daily throughputs. Thus, if the product demand is projected to 750 finished parts by the end of the day, there are two different possibilities for choosing the container capacity. The first possibility is to choose a container with capacity of 75 parts per container, and the other is 50 parts per container. For this specific case, it is better to choose the second option because logically, this type of container has higher number of daily cycles. The higher number of cycles reduces the processing time per container. This makes the system more flexible and resistant to external disruptions including change in demand, defects, change of the product etc. Most importantly, with this type of container, whenever an error occurs, less number of parts will be affected by it.

It is the same when the needed daily throughput is 720 finished parts per day. Furthermore, this simulation model can be a perfect basis for future experiments. These can include other important factors, such as: delays, defects, scrap percentage, product changes, workers overload etc.



Figure 5: Experiment results

\section{CONCLUSION}

The main goal of every organization is to always design optimized processes. These processes should be implemented wasting minimum money, while focusing on the client's needs.

Hence, it can be concluded that KANBAN is the right tool for creating such processes. On the other hand, the simulations can be utilized as a tool for fast and reliable designing of the KANBAN system. The research presented in this article deals with the decisions on what and when needs to be produced, having in mind the lowest possible costs for transport, storage, control etc. Moreover, in this paper, it is clearly shown that with the aid of a simulation package, engineers can make simulation models which shorten the time for designing, planning and analyzing possible outcomes of the KANBAN system implementation.

The simulation model discussed in this paper opens new horizons and opportunities for managers, offering them ideas on how to improve the productivity of their companies.

\section{REFERENCES}

Banks, J., Carson, J., Nelson, B. L., \& Nicol, D. (2004). Discrete-Event System Simulation (4th Edition): Prentice Hall.

Gross, J. M., \& McInnis, K. R. (2003). Kanban Made Simple: Demystifying and Applying Toyota's Legendary Manufacturing Process: AMACOM.

Hao, Q., \& Shen, W. (2008). Implementing a hybrid simulation model for a Kanban-based material handling system. Robotics and Computer-Integrated Manufacturing, 24(5), 635-646. doi: 10.1016/j.rcim.2007.09.012

Lödding, H. (2013). Handbook of Manufacturing Control. Fundamentals, description, configuration. Berlin: Springer.

Minovski, R. (2007). Management Information Systems. Skopje: UKIM.

Monden, Y. (1998). Toyota Production System: An Integrated Approach to Just-In-Time: Chapman \& Hall. 
Müller, E., Tolujew, J., \& Kienzle, F. (2012). PushKanban - a kanban-based production control concept for job shops. Production Planning and Control: The management of operations(April), 113. doi: 10.1080/09537287.2012.701021

Ohno, T., \& Bodek, N. (1988). Toyota Production System: Beyond Large-Scale Production: Productivity Press.

Pisuchpen, R. (2012). Integration of JIT flexible manufacturing, assembly and disassembly using a simulation approach. Assembly Automation, 32(1), 51-61. doi: 10.1108/01445151211198719

Robinson, S. (2004). Simulation: The Practice of Model Development and Use (Vol. 67): John Wiley\& Sons Ltd.
Siemens. Plant Simulation. from http://www.plm.automation.siemens.com/en_us/pro ducts/tecnomatix/plant_design/plant_simulation.sht $\underline{\mathrm{ml}}$

Sugimori, Y., \& Kusunoki, K. (1977). Toyota production system and kanban system materialization of just-in-time and respect-forhuman system. ... Journal of Production ...(April 2013), 37-41.

Welgama, P. S., Mills, R. G. J., \& Osmond, G. (1995). Use of simulation in the design of a JIT system. International Journal of Operations \& Production Management, 15(9), 245-260. 